\title{
Reproductive endocrine effects of acute exposure to toluene in men and women
}

\author{
Ulrike Luderer, Michael S Morgan, Carl A Brodkin, David A Kalman, Elaine M Faustman
}

\begin{abstract}
Objectives-Despite observation of adverse reproductive effects of toluene, including alterations of serum gonadotropins (luteinising hormone (LH) and follicle stimulating hormone (FSH)) in humans, little is known of the mechanism of toxicity. The hypothesis was tested that toluene acutely suppresses pulsatile gonadotropin secretion by measuring $\mathrm{LH}$ and FSH at frequent intervals during controlled exposure to toluene. Methods-Women in the follicular and luteal phases of the menstrual cycle and men were randomised to inhale filtered air with or without $50 \mathrm{ppm}$ toluene through a mouthpiece for 3 hours $(19 \%$ of the OSHA permissable exposure limit). Blood was sampled by intravenous catheter at 20 minute intervals for 3 hours before, 3 hours during, and 3 hours after exposure. Plasma LH, FSH, and testosterone were measured. Pulse amplitude, pulse frequency, and mean concentrations of LH and FSH for each of the 3 hour periods before, during and after exposure to toluene versus sham exposure were calculated with the ULTRA pulse detection program and compared by analysis of variance (ANOVA) with repeated measures.
\end{abstract}

Occupational and

Environmental Health, University of

California, Irvine, CA,

USA

U Luderer

Department of Environmental Health

M S Morgan

C A Brodkin

D A Kalman

E M Faustman

Occupational and Environmental Medicine Program, University of Washington, Seattle, Washington, USA

U Luderer

C A Brodkin

Correspondence to: Dr Ulrike Luderer,

University of California at

Irvine, Center for

Occupational and

Environmental Health,

19722 MacArthur

Boulevard, Irvine, CA92612,

USA.

Accepted 15 June 1999
Results-In men mean concentrations of LH showed a significant interaction $(p<0.05)$ between exposure and sampling period, with a greater LH decline during exposure to toluene than sham exposure. However, there was no concomitant effect on testosterone concentrations. The LH pulse frequency of women in the luteal phase showed a trend towards a significant interaction between exposure and sampling period $(p=0.06)$, with a greater decline in pulse frequency during exposure to toluene than sham exosure. There were no other significant effects of exposure to toluene.

Conclusions-Three hour exposure to 50 ppm toluene did not result in abnormal episodic LH or FSH secretion profiles, however, subtle effects on LH secretion in men and women in the luteal phase were found. The clinical relevance of these effects is unclear, indicating the need for further study of reproductive function in exposed workers.

(Occup Environ Med 1999;56:657-666)

Keywords: solvents; luteinising hormone; follicle stimulating hormone
Recommended human occupational and environmental exposure limits to solvent chemicals have been based primarily on studies designed to detect global effects such as encephalopathy. Most of these studies were not designed to detect subtle alterations in hypothalamicpituitary-gonadal function that might adversely affect the reproductive health of millions of exposed workers. The aromatic solvent toluene, which is widely used in such diverse manufacturing industries as shoes, textiles, electronic components, and plastics exemplifies this dilemma. Despite several studies suggesting adverse reproductive effects of exposures to mixed solvents ${ }^{1-5}$ and a few studies implicating toluene specifically, ${ }^{6-8}$ very little is known about the mechanisms by which toluene might disrupt reproductive function.

Although relatively little research has been undertaken to examine the human reproductive effects of solvent compounds, occupational exposure to organic solvents has been reported to be associated with decreased fecundability, ${ }^{3}{ }^{4}$ infertility, ${ }^{5}$ dysmenorrhoea, and irregular menstrual cycles. ${ }^{126}$ Similarly, studies of reproductive endocrine function in male rotogravure workers exposed exclusively to toluene reported lower luteinising hormone (LH), follicle stimulating hormone (FSH), and testosterone concentrations. ${ }^{78}$ The findings of diminished $\mathrm{LH}, \mathrm{FSH}$, and testosterone in these studies suggest a primary suppressive effect of toluene on $\mathrm{LH}$ and FSH secretion at the pituitary level or suppression of hypothalamic gonadotropic releasing hormone $(\mathrm{GnRH})$ secretion or both. A central effect of toluene on reproductive function is further supported by neuroanatomical studies in both humans and animals showing that toluene preferentially distributes to the brainstem, including the hypothalamus. ${ }^{9}$ Moreover, in female rats exposure to toluene reduces GnRH content in the preoptic area of the hypothalamus, ${ }^{10}$ and in male rats it alters hypothalamic noradrenaline (norepinephrine), ${ }^{11} 12$ the primary neurotransmitter involved in regulation of $\mathrm{GnRH}$ secretion. ${ }^{13}$

Previous investigations of the effects of toluene on gonadotropin secretion have been limited by the use of single measurements of gonadotropin concentrations after exposure. As these hormones are known to be secreted episodically, with significant minute to minute fluctuations in concentration particularly for $\mathrm{LH}$, only large differences in hormone concentrations are likely to be detected with single samples. ${ }^{14-18}$ The ability to detect differences in gonadotropin concentrations among groups can be greatly enhanced by multiple 
sampling, ${ }^{14}$ which has the additional advantage of enabling the detection of $\mathrm{LH}$ pulse frequency, which directly reflects GnRH pulse frequency. ${ }^{19}$

The purpose of this study, therefore, was to use the technique of repeated blood sampling to test the hypotheses that $(a)$ acute exposure to toluene suppresses episodic gonadotropin secretion in men and women, $(b)$ that this effect is mediated through a central hypothalamic effect suppressing $\mathrm{GnRH}$ pulse frequency, and (c) to determine whether such effects on the hypothalamic-pituitary axis occur at concentrations within permissible standards.

\section{Methods}

\section{STUDY DESIGN}

The study used a controlled, blinded, interventional experimental design, with reproductive hormone concentrations ( $\mathrm{LH}, \mathrm{FSH}$ ) determined before, during, and after exposure to inhaled toluene. The research protocols were approved by the University of Washington Human Subjects Review Committee. All subjects gave written, informed consent. Blood sampling was conducted under the supervision of the Clinical Research Center of the University of Washington Medical Center.

\section{RECRUITMENT OF SUBJECTS}

Men and women aged 19-45 were recruited from the University and surrounding community through posters and advertisements in the printed media. Eligibility criteria included $(a)$ absence of clinically important chronic disease, (b) no active exposure to solvents, (c) no cigarette smoking or other substance misuse, $(d)$ absence of menstrual or fertility disorders or history of adverse pregnancy outcomes, (e) no current pregnancy, confirmed by measurement of serum human chorionic gonadotropin (HCG) 1 day before the study day, $(f)$ no hormonal contraceptive use, $(g)$ use of reliable non-hormonal contraceptive method.

DETERMINATION OF MENSTRUAL CYCLE IN WOMEN

A menstrual history was elicited to establish the regularity and timing of menstrual cycles. Subjects had to have regular menstrual cycles during the 6 months preceding enrolment to the study. Mid-follicular phase was defined as 5-9 days after the onset of menses for a 28 day cycle. ${ }^{20}$ Mid-luteal phase was defined as 5-9 days before the expected first day of the next cycle for a 28 day cycle. ${ }^{20}$ For cycles not 28 days in duration, the luteal phase was assumed to be 14 days in duration, with the appropriate adjustments made for the follicular phase. ${ }^{21}$

EXPERIMENTAL PROTOCOLS TO ASSESS EFFECTS OF EXPOSURE TO TOLUENE ON PULSATILE GONADOTROPIN SECRETION

Men or regularly cycling women aged $19-45$ were randomised for exposure to a mixture of toluene and filtered air ( $n=6$ mid-luteal phase, $\mathrm{n}=5$ mid-follicular phase, $\mathrm{n}=5 \mathrm{men}$ ) or to filtered air alone ( $n=5$ mid-luteal, $n=5$ midfollicular, $n=5$ men) for 3 hours as described below. The stages of the menstrual cycle were chosen because there is no diurnal variation in LH or FSH during these stages and no mid-cycle preovulatory gonadotropin surges. ${ }^{16}{ }^{18}$ Although there is no diurnal variation in FSH secretion in men, about $10 \%$ of men have increased LH pulse frequency during sleep. ${ }^{17}$ Therefore, samples were taken from awake subjects during normal waking hours.

Venous blood samples were collected from a forearm catheter into heparinised Vacutainer tubes (Becton-Dickinson, Franklin Lakes, NJ, USA) after clearing the line of saline. Samples were collected at 20 minute intervals for 9 hours ( 3 hours before onset of exposure, 3 hours during exposure, and 3 hours after the end of exposure). Sampling periods of 3 hours were judged to be sufficient to determine hormonal pulse frequency. A time interval of 20 minutes between samples has been shown to permit detection of gonadotropin pulses in humans. ${ }^{20}$ Subjects were given breakfast and lunch and were free to move about between blood sampling, except during the exposure period when they remained seated in a chair.

Samples were refrigerated for up to 9 hours at $4^{\circ} \mathrm{C}$, then were centrifuged, and plasma was collected and stored at $-80^{\circ} \mathrm{C}$ until subsequent $\mathrm{LH}$ and FSH fluoroimmunoassay. Toluene concentration in whole blood drawn at the end of the exposure period was measured on the day of the exposure for subjects from both groups, exposure to toluene, and sham exposure. The peak blood concentration of solvent was known to be reached at the end of the exposure, based on previous studies. ${ }^{22}$ Testosterone concentrations were also measured in three plasma samples from the end of the period before exposure, the end of the exposure period, and the end of the period after exposure in the men only.

EXPOSURE SYSTEM

Subjects breathed air containing 50 ppm toluene for 180 minutes. This is equivalent to $18.75 \mathrm{ppm} 8$ hour time weighted average (TWA) or $37.5 \%$ of the American Conference of Government Industrial Hygienists (ACGIH) maximum recommended daily exposure of 50 ppm 8 hour TWA $^{23}$; and $18.8 \%$ of the United States Occupational Safety and Health Administration (OSHA) permissible exposure limit. This level of exposure was chosen because effects on gonadotropin secretion have been reported in workers exposed to similar concentrations, ${ }^{78}$ because most current occupational exposure limits range between 50 and $100 \mathrm{ppm}, 8$ hour TWA, ${ }^{23}$ and because it is a level which occurs in many workplaces. ${ }^{24}$

The exposure system consists of a dynamic atmosphere generator, a gated inhalation port, and sensors for monitoring toluene concentration. ${ }^{25}$ Briefly, a solvent syringe pump (Harvard apparatus infusion/withdrawal pump model 920; Holliston, MA, USA) delivers a constant flow rate of solvent to a heater where it is vaporised; solvent vapour is diluted with filtered air in a glass mixing chamber, and from there the air-toluene mixture flows to a mouthpiece. Subjects with nose clips inhale the mixture in a seated position. Two one way valves in 
the mouthpiece prevent reinhalation of exhaled air. During the exposure period the inhaled toluene concentration is continuously monitored by photoionisation detector.

ASSAY OF BIOLOGICAL SAMPLES

Hormone assays

Plasma LH and FSH were measured with Wallac DELFIA time resolved fluoroimmunoassays (Turku, Finland) by a blinded technician. Each assay uses two monoclonal antibodies (mouse anti-human) directed against two different antigenic determinants of the gonadotropin. For the present study each subject sample was run in duplicate, and the mean of the two concentrations was used for statistical calculations and graphical presentation of the data. Serum control pools of known low, medium, and high concentrations were run in quadruplicate with each assay. For the present studies the coefficients of variation (CVs) between assays for $\mathrm{LH}$ ranged from $9.0 \%$ to $11.6 \%$ for the different control pools, and for FSH the CVs between assays ranged from $6.0 \%$ to $21.8 \%$, which are typical ranges for gonadotropin immunoassays. ${ }^{15} 20$ Plasma testosterone was measured by radioimmunoassay with reagents from the World Health Organisation match reagent programme by previously described methods. ${ }^{26}$ Between assay CVs ranged from $14 \%$ to $24 \%$ for the different control serum pools.

\section{Toluene assay}

Blood drawn during the exposure was analysed for toluene with a modification of the static headspace/on column cryofocusing analysis method of Dills et al. ${ }^{27}$ Toluene contamination of the heparinised Vacutainer tubes has been found to be negligible in comparison with the blood concentrations reached during and for several hours after a 3 hour, 50 ppm exposure.

PULSE ANALYSIS

Pulses of $\mathrm{LH}$ and FSH were identified with the ULTRA pulse detection program. ${ }^{28}$ This pro-

Table 1 Characteristics of participants

\begin{tabular}{|c|c|c|c|}
\hline & $\begin{array}{l}\text { Exposure to toluene mean } \\
\text { (range) }\end{array}$ & $\begin{array}{l}\text { Sham exposure mean } \\
\text { (range) }\end{array}$ & $p$ Value \\
\hline \multicolumn{4}{|c|}{ Women in the follicular phase: } \\
\hline Age (y) & $27.4(22-31)$ & $24.5(20-26)$ & 0.24 \\
\hline Weight (kg) & $60.9(48.5-67.4)$ & $93.0(59.5-127.5)$ & 0.13 \\
\hline Height $(\mathrm{cm})$ & $163.5(150-168)$ & $166.5(162.0-170.5)$ & 0.46 \\
\hline $\mathrm{BMI}$ & $22.7(21.4-24.2)$ & $33.6(20.5-45.4)$ & 0.15 \\
\hline Adipose tissue (\%) & $23.3(21.3-26.5)$ & $29.1(20.7-34.3)$ & 0.17 \\
\hline Day of study^ & $6.6(5$ to 8$)$ & $6.4(5$ to 8$)$ & 0.83 \\
\hline \multicolumn{4}{|c|}{ Women in the luteal phase: } \\
\hline $\mathrm{n}$ & 5 & 4 & \\
\hline Age (y) & $25.8(19-36)$ & $24.8(20-33)$ & 0.81 \\
\hline Weight (kg) & $67.8(55.1-92.0)$ & $70.0(58.0-89.0)$ & 0.83 \\
\hline Height $(\mathrm{cm})$ & $162.7(157-175.5)$ & $170.8(162.0-177.0)$ & 0.12 \\
\hline BMI & $25.5(22.2-34.6)$ & $24.0(19.8-28.4)$ & 0.59 \\
\hline Adipose tissue (\%) & $25.4(21.9-28.7)$ & $22.6(20.8-26.0)$ & 0.12 \\
\hline Day of study & $-6.6(-5$ to -9$)$ & $-6.5(-5$ to -8$)$ & 0.93 \\
\hline \multicolumn{4}{|l|}{ Men: } \\
\hline $\mathrm{n}$ & 5 & 5 & \\
\hline Age (y) & $30.2(23-44)$ & $32.8(23-39)$ & 0.59 \\
\hline Weight (kg) & $82.7(73.5-92)$ & $78.1(70-85.5)$ & 0.30 \\
\hline Height $(\mathrm{cm})$ & $180.3(177-187)$ & $176.8(167-182)$ & 0.32 \\
\hline BMI & $25.5(22.2-29.0)$ & $25.0(24.2-25.8)$ & 0.69 \\
\hline Adipose tissue (\%) & $18.9(16.5-23.4)$ & $19.4(15.7-23.9)$ & 0.88 \\
\hline
\end{tabular}

^Relative to first day of present menstrual cycle.

†Relative to expected first day of next menstrual cycle. gram takes as input the sample hormone concentrations, the CVs for the concentration ranges of the assay, and a threshold expressed in terms of a multiple of assay CVs. The program proceeds by eliminating all increments and decrements from the series that do not exceed the specified multiple of local assay CVs. The remaining peaks are considered to be relevant pulses. Previous studies have used thresholds of $2 \times$ to $4 \times$ assay $\mathrm{CVs}^{15}{ }^{18}$ or $2 \times$ assay standard deviation ${ }^{161720}$ to optimise detection of actual pulses while minimising false positives. Based on initial comparisons of $2 \times$ and $3 \times \mathrm{CV}$ thresholds, a $3 \times \mathrm{CV}$ threshold was chosen for this study to minimise false positive pulses.

\section{STATISTICAL ANALYSIS}

The study analysis used a repeated measures analysis of variance (ANOVA) design. In this design the dependent variables (mean concentrations, pulse amplitude, and pulse frequency of $\mathrm{LH}$ and $\mathrm{FSH}$ ) are measured repeatedly for each subject. Therefore, as well as the variable "exposure" between subjects (toluene or sham), there is also a variable "sampling period" within subjects (before, during, and after exposure), and the variable of most interest is the interaction term between exposure and sampling period.

Three female subjects were excluded from the final analyses because their LH and FSH profiles were not consistent with the expected stage of the menstrual cycle: one woman in the follicular phase with sham exposure; one woman in the luteal phase exposed to toluene; and one woman in the luteal phase with sham exposure. Pulse amplitude, pulse frequency, and mean hormone concentrations for the remaining subjects were assessed from the results of the ULTRA analysis and were compared before, during, and after exposure with repeated measures ANOVA and analysis of covariance (ANCOVA). The ANCOVAs were performed with age, body mass index (BMI, calculated as weight $(\mathrm{kg}) /$ height $\left.(\mathrm{m})^{2}\right)$, and adipose tissue fraction assessed by skin fold thickness ${ }^{29}$ as covariates. These covariates were chosen because gonadotropin concentrations in both sexes increase with age ${ }^{30}{ }^{31}$; obesity is associated with changes in gonadotropin concentrations, ${ }^{32-34}$ and toluene body burdens are influenced by body composition. ${ }^{22}$ Differences were considered significant if the $p$ value was $\leqslant 0.05$.

When data for a particular variable were not normally distributed, a log transformation was used. If the transformed data were still not normally distributed (as was the case for $\mathrm{LH}$ and FSH pulse frequency in all of the groups), the Kruskal-Wallis test for non-parametric data was used to compare the sham group with the group exposed to toluene during the exposure and after the exposure.

\section{Results}

DEMOGRAPHIC INFORMATION AND PHYSICAL CHARACTERISTICS OF STUDY PARTICIPANTS Age, height, weight, BMI, and adipose tissue fraction for the study groups are summarised in 

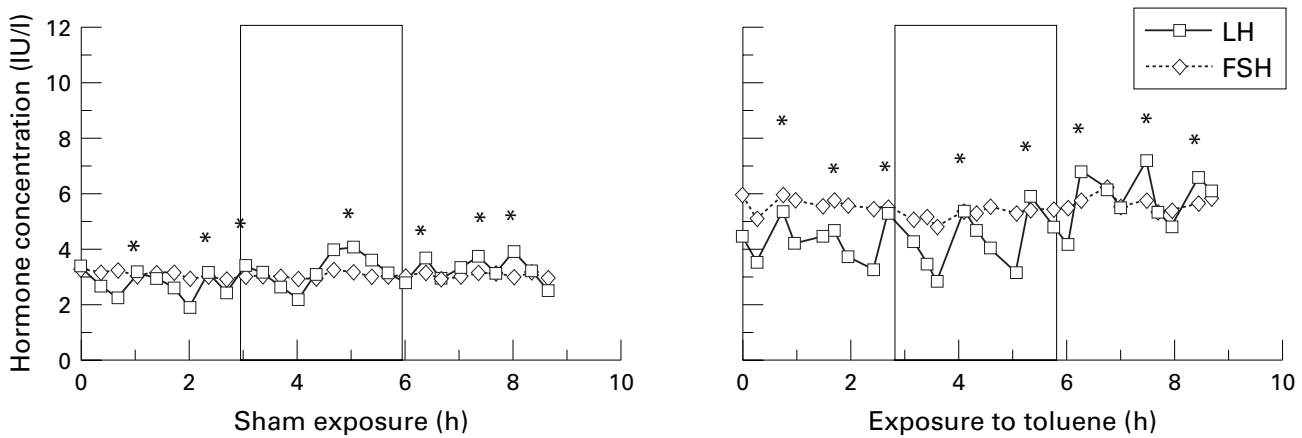

Figure 1 LH and FSH secretion profiles in representative, individual women in the follicular phase exposed and not exposed to toluene. Blood samples, indicated by the open symbols, were drawn every 20 minutes for 9 hours. Exposure interval is indicated by the rectangle. Significance for $\mathrm{LH}^{\star}$ and $F S H^{\wedge}$ pulses were assessed by the ULTRA program ${ }^{28}$ with a difference of $3 \times$ local assay coefficients of variation from trough to peak as the criterion.

table 1 . There were no significant differences between the sham group and the group exposed to toluene, despite the presence of one woman in the follicular phase with sham exposure who had a high BMI and adipose tissue fraction. Moreover, the results of this and subsequent analyses did not substantially change when data from this subject were removed.

SYMPTOMS RELATED TO EXPOSURE

None of the subjects complained of any headaches, lassitude, or loss of appetite, which have been published in association with exposures to toluene of 50-200 ppm. ${ }^{23}$ Both groups of subjects complained of mild discomfort related to sitting relatively still for 3 hours and of a dry mouth.

BLOOD TOLUENE CONCENTRATIONS IN MEN AND WOMEN AFTER CONTROLLED EXPOSURE

Inhalational exposure to $50 \mathrm{ppm}$ toluene for 3 hours resulted in mean (SEM) peak blood toluene concentrations of $4.90(0.97) \mathrm{nmol} / \mathrm{ml}$ (range 3.58-6.79) in men; $3.65(1.02) \mathrm{nmol} / \mathrm{ml}$ in women during the luteal phase (range 0.23 $5.72)$; and $5.57(1.09) \mathrm{nmol} / \mathrm{ml}$ in women during the follicular phase (range 2.32-7.96). One outlier was identified: a woman in the luteal phase with exposure to toluene. Analyses performed without this outlier did not substantially differ from analyses with the outlier included, so the outlier was included in the results. Mean toluene concentrations in subjects with sham exposure also did not differ by sex or cycle stage $(0.013(0.004) \mathrm{nmol} / \mathrm{ml}$ in men, $0.010(0.005) \mathrm{nmol} / \mathrm{ml}$ in luteal women, $0.011(0.006) \mathrm{nmol} / \mathrm{ml}$ in follicular women).

EFFECT OF EXPOSURE TO TOLUENE ON LH AND FSH IN WOMEN DURING FOLLICULAR AND LUTEAL PHASES

Figure 1 depicts representative individual LH and FSH profiles before, during, and after sham exposure and exposure to toluene, respectively, in women during the follicular phase. High frequency, low amplitude $\mathrm{LH}$ pulses and infrequent, low amplitude $\mathrm{FSH}$ pulses occurred in both groups of women studied during days 5-9 of their menstrual cycles.

ANCOVA with age, BMI, or adipose tissue fraction as the covariate showed no significant effect of these possible covariates on $\mathrm{LH}$ or FSH secretion. Therefore, only the results of the unadjusted analyses will be reported here. The mean LH and FSH concentrations, pulse amplitudes, and pulse frequencies are depicted in figure 2 for women in the follicular phase. There was no significant effect of exposure to toluene alone, nor were there significant interactions between exposure and sampling period, on LH mean concentration, pulse amplitude or pulse frequency, or on FSH mean or $\log \mathrm{FSH}$ mean concentrations in women in the follicular phase. There was a significant effect of sampling period alone $(\mathrm{p}=0.04)$ on $\mathrm{LH}$ mean concentration and $\log \mathrm{LH}$ mean concentration, in the form of slightly increasing mean $\mathrm{LH}$ concentrations in both groups of women over the three sampling periods. Few significant FSH pulses were found in the group exposed to toluene and no FSH pulses were found in the group with sham exposure. Therefore, analyses were not done for FSH pulse amplitude or pulse frequency in women in the follicular phase.

Figure 3 depicts representative individual $\mathrm{LH}$ and FSH profiles in women in the luteal phase. In these women studied during days 19-23 of their cycles low frequency, high amplitude LH pulses and infrequent, small amplitude $\mathrm{FSH}$ pulses were found.

The mean LH and FSH concentrations, pulse amplitudes, and pulse frequencies are depicted in figure 4 for women in the luteal phase. There was no significant effect of exposure to toluene in these women, nor were there significant interactions between exposure and sampling period, on LH mean concentrations, pulse amplitude, or pulse frequency. However, there was a trend towards a significant interaction $(p=0.06)$ between sampling period and exposure on $\mathrm{LH}$ pulse frequency, with pulse frequency apparently reduced during the exposure period in the women with exposure to toluene compared with the sham exposure. There was a significant effect of sampling period alone on mean concentrations $(p=0.02)$ and pulse frequency of $\mathrm{LH}(\mathrm{p}=0.04)$, reflecting the occurrence of most of the luteal phase pulses during the intervals before and after exposure in both exposure groups. There was no significant effect of exposure, nor was there interaction between exposure and sampling 

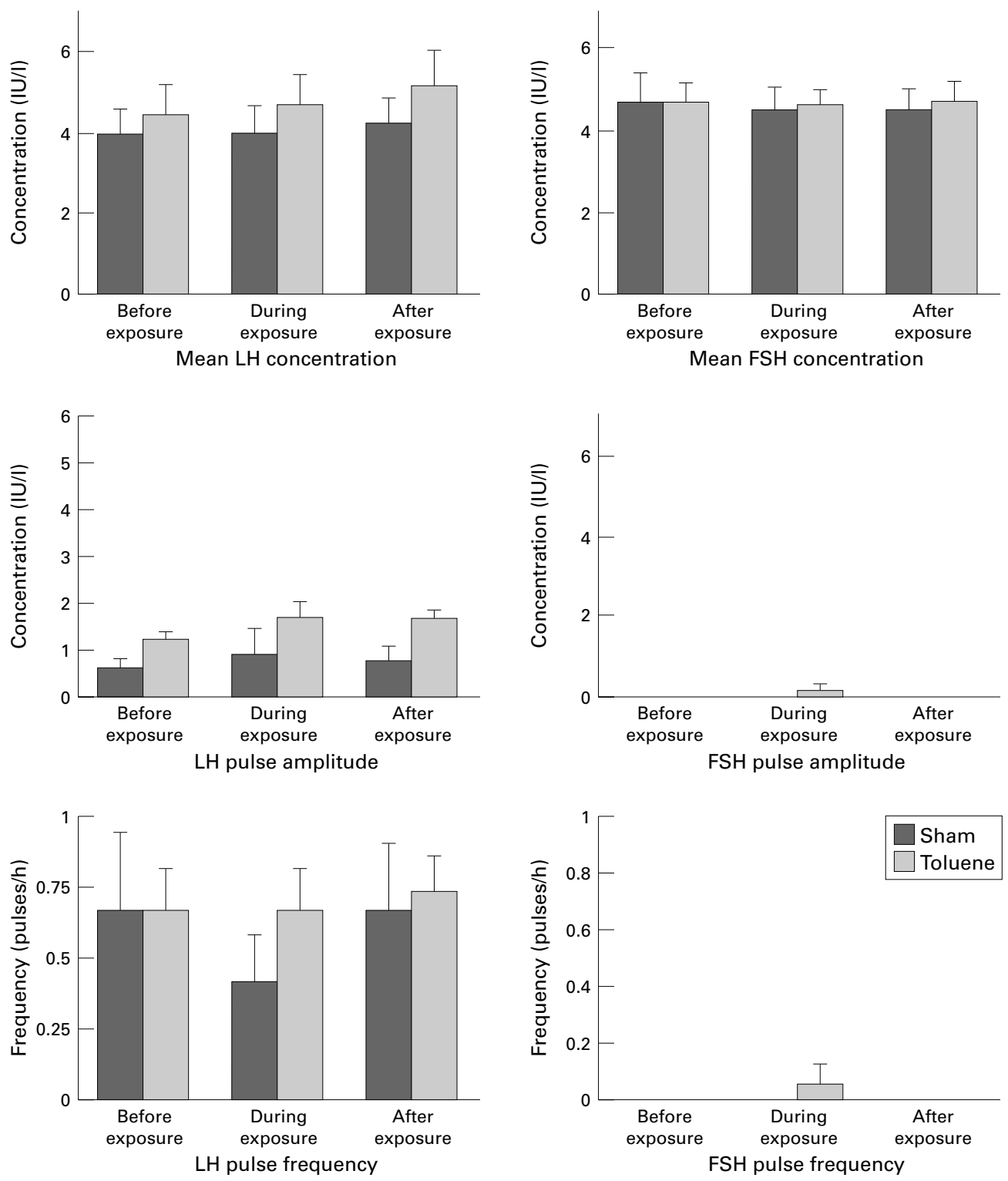

Figure 2 LH and FSH secretion in women in the follicular phase with sham exposure and exposure to toluene. Bars show mean (SEM) for each 3 hour sampling period for groups exposed $(n=5)$ or not exposed $(n=4)$ to toluene, $p<0.05$, ANOVA, effect of sampling period on LH mean concentration.
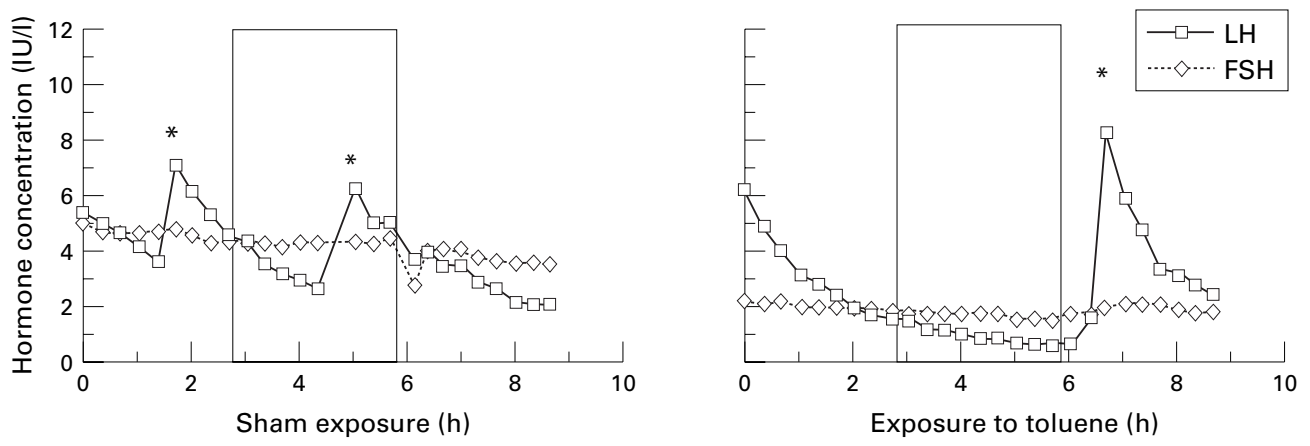

Figure 3 LH and FSH secretion profiles in representative women in the luteal phase exposed or not exposed to toluene. Exposure interval is indicated by the rectangle. Significant $\mathrm{LH}^{\star}$ and $F S H^{\wedge}$ pulses are indicated. Further details in legend to figure 1 . 

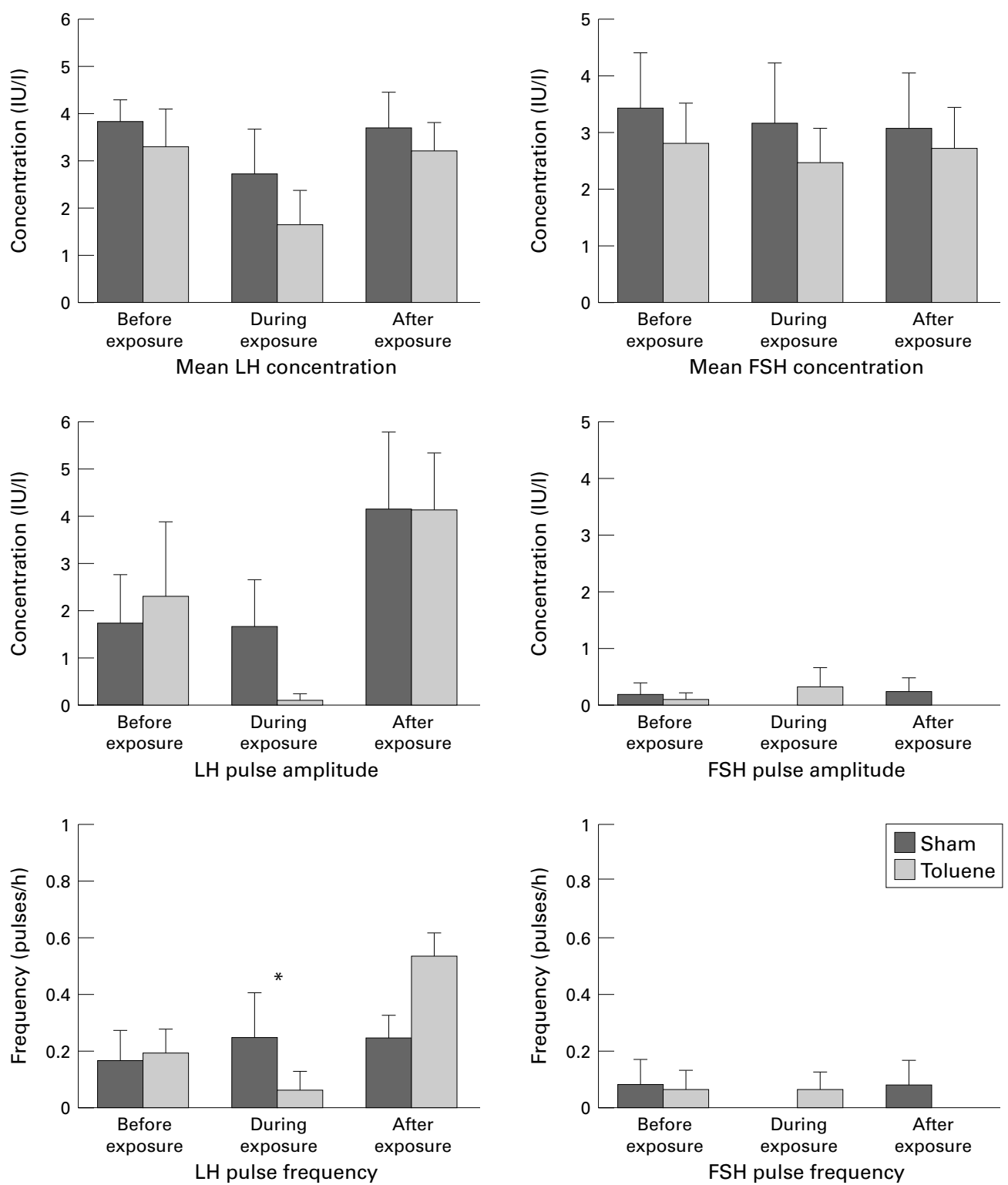

Figure 4 LH and FSH secretion in women in the luteal phase exposed or not exposed to toluene. Bars show mean (SEM) for each 3 hour sampling period for groups with sham exposure $(n=4)$ and exposure to toluene $(n=5)$. ${ }^{*} p=0.06$ for the interaction between exposure and sampling period on LH pulse frequency. $p<0.05$ by ANOVA for the effect of sampling period on LH mean concentration and pulse frequency and on FSH mean concentration.

period on mean FSH concentrations; however, there was a borderline significant effect of sampling period alone $(\mathrm{p}=0.05)$, reflecting slightly higher mean FSH concentrations before exposure than during and after exposure in both sham and exposed groups. There were no significant effects on FSH pulse amplitude or frequency.

EFFECT OF EXPOSURE TO TOLUENE ON LH AND FSH IN MEN

Figure 5 depicts representative individual $\mathrm{LH}$ and FSH profiles before, during, and after sham exposure and exposure to toluene in men. In both exposure groups of men the LH pulses consisted of low amplitude fluctuations occurring at frequencies varying among men from about $1 / 90$ minutes to $1 / 3$ hours. In comparison FSH fluctuations were small and infrequent in both groups.
Analyses by ANCOVA performed with age, BMI, or adipose tissue fraction as the covariate showed a significant effect of age on LH pulse frequency, but no other significant effects of these covariates on $\mathrm{LH}$ or FSH secretion, nor on testosterone secretion. There was no significant effect of treatment or significant interaction between treatment and sampling period either when the LH pulse frequency data were analysed by ANOVA or by ANCOVA with age as a covariate. Therefore, the results of the unadjusted ANOVAs are reported here. The mean LH and FSH concentrations, pulse amplitudes, and pulse frequencies in men with sham exposure and exposure to toluene are depicted in figure 6 . There was no significant effect of treatment alone on any variable of $\mathrm{LH}$ secretion; however, there was a significant interaction $(p<0.05)$ between treatment and sampling period on LH mean concentration. 

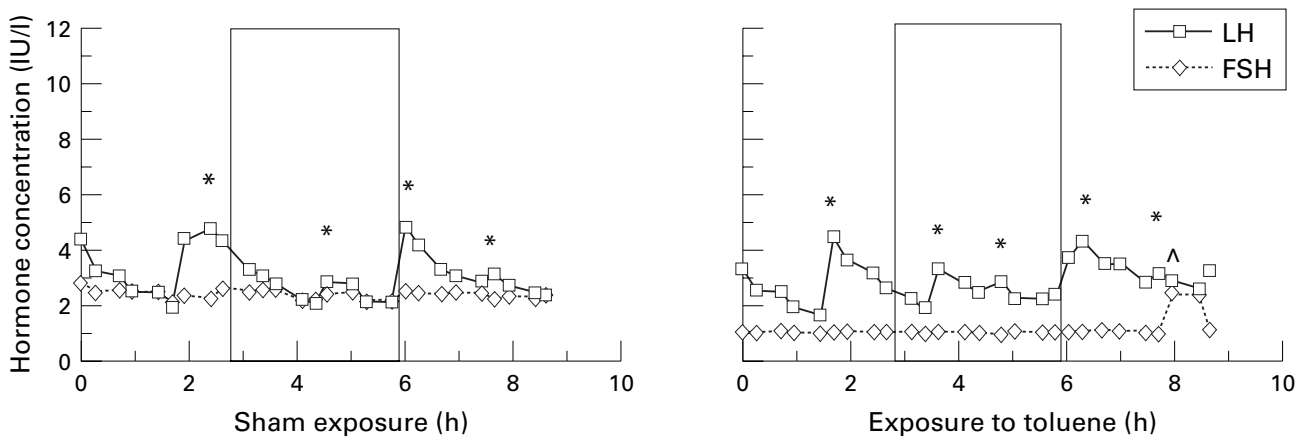

Figure $5 \mathrm{LH}$ and FSH secretion profiles in representative men with sham exposure and exposure to toluene. Exposure interval is indicated by the rectangle. Significant $\mathrm{LH}^{\star}$ and $\mathrm{FSH}^{\wedge}$ pulses are indicated. Further details from legend to figure 1.
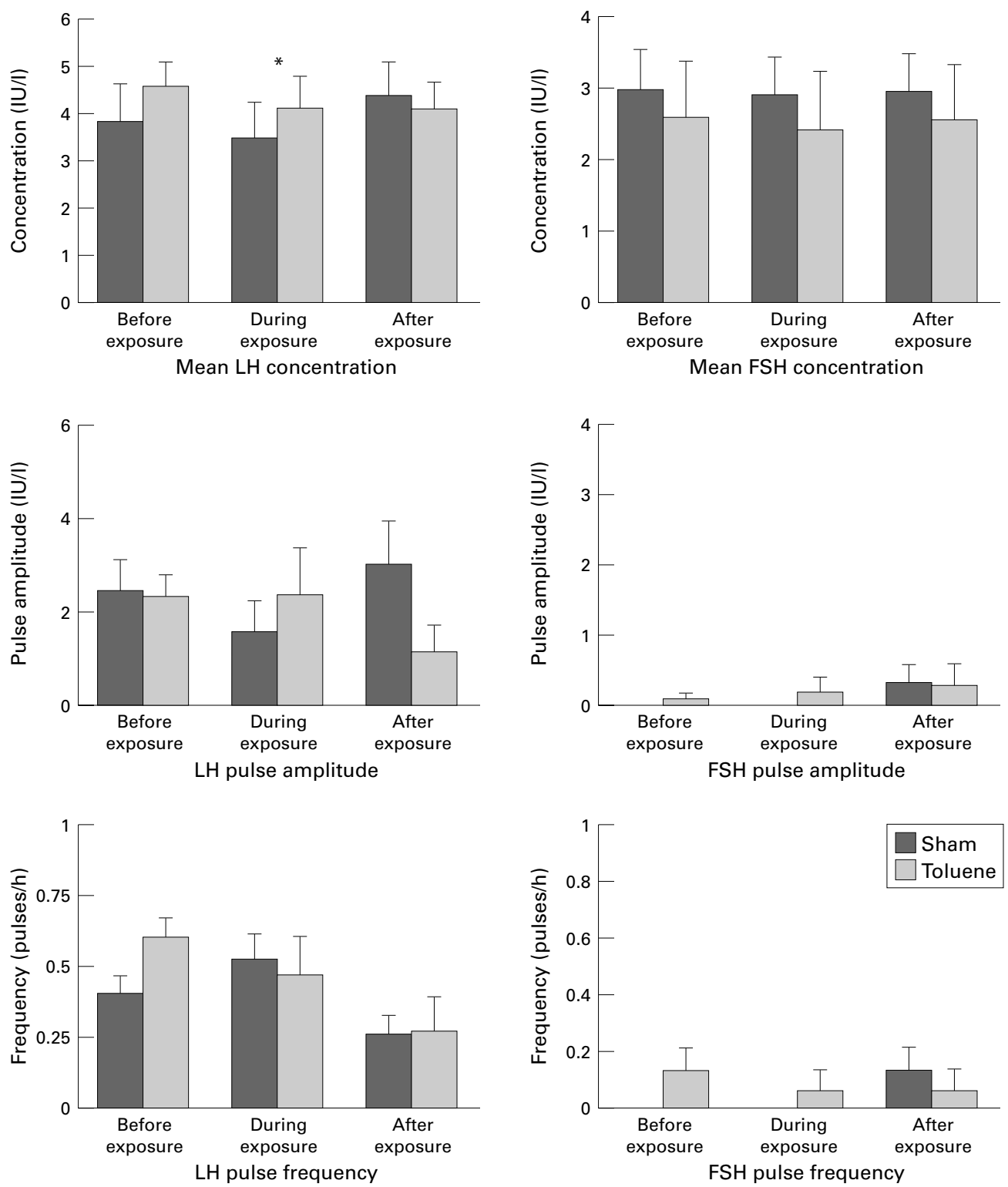

Figure 6 LH and FSH secretion in men with sham exposure and exposure to toluene. Bars show mean (SEM) for each of the 3 hour sampling periods for $n=5$ subjects/group. ${ }^{\star} p<0.05$ by ANOVA for the interaction between sampling period and exposure on LH mean concentration. 
Table 2 Mean (SEM, range) testosterone concentrations in men

\begin{tabular}{lll}
\hline Sampling period & Sham exposure $($ nmol/l) $n=5$ & Exposure to toluene $($ nmolll) $n=5$ \\
\hline Before exposure & $17.5(2.1,11.6-20.6)$ & $19.6(1.1,16.3-22.2)$ \\
During exposure & $17.0(2.2,13.3-23.3)$ & $22.9(2.8,17.2-29.8)$ \\
After exposure & $16.9(0.7,14.3-18.1)$ & $19.8(1.9,13.7-25.3)$ \\
\hline
\end{tabular}

There were no significant differences among groups or time intervals by ANOVA.

This was in the form of slightly declining mean $\mathrm{LH}$ concentrations over the exposure intervals in the men exposed to toluene, whereas LH concentrations decreased and then increased slightly during and after sham exposure. There were no significant effects of treatment or exposure interval on FSH mean concentration, $\log$ FSH mean concentration, pulse amplitude, or pulse frequency in men.

Plasma testosterone concentrations measured at the end of each of the three time intervals did not differ by exposure or sampling period (table 2).

\section{Discussion}

The present study was designed to test the hypothesis that exposure to toluene at $50 \mathrm{ppm}$ for 3 hours acutely suppresses LH and FSH secretion through suppression of hypothalamic GnRH pulse frequency in men and women. This exposure is equivalent to $38 \%$ of the ACGIH threshold limit value TWA, $38 \%$ of the British regulatory exposure limit, and $19 \%$ of the United States and German regulatory exposure limits. ${ }^{23}$ Exposure to toluene at this concentration did not result in abnormal $\mathrm{LH}$ or FSH pulse amplitude, pulse frequency, or mean concentrations in either men or women, as defined by previous studies of spontaneous episodic LH and FSH secretion in young men $^{15}{ }^{17}$ and in women in either the luteal or follicular phase. ${ }^{16182035}$ Of interest, however, was (a) a trend towards a significant decline in $\mathrm{LH}$ pulse frequency in women in the luteal phase during exposure to toluene $(p=0.06)$, and $(b)$ a small, but significant, decline in $\mathrm{LH}$ mean concentrations in men exposed to toluene compared with the sham group.

The clinical relevance of the observed effects is unclear. The mean LH concentrations in all of the men remained within the normal ranges for LH mean concentrations which were established by the laboratory which performed the assays (personal communication). Therefore, the observed effect on mean LH concentrations may represent a subclinical effect of toluene on the pituitary or hypothalamus without physiological impact on testicular testosterone secretion. The trend towards decreased LH pulse frequency in women during the luteal phase exposed to toluene is also difficult to interpret. It may be coincidental as LH pulse amplitude and mean concentration also declined during sham exposure, although not to the same degree as during exposure to toluene. Although the very low LH pulse frequency found in the women exposed to toluene during the 3 hour exposure period falls outside of the normal range of about $0.2-0.5$ pulses/hour during a 24 hour period in the mid-luteal phase, periods of $4-5$ hours in duration with no notable LH pulses occur commonly in women during this phase. ${ }^{16} 182035$ For comparison LH pulse frequencies of $0-0.25$ pulses/hour have been reported in women with hypothalamic amenorrhoea or oligomenorrhoea. ${ }^{36}{ }^{37}$ Because of the low LH pulse frequency in normal women during the luteal phase, longer exposures with frequent blood sampling may be necessary to find whether exposure to toluene suppresses LH pulse frequency in women during the luteal phase.

As each peripheral $\mathrm{LH}$ pulse is a reflection of a hypothalamic GnRH pulse, ${ }^{19}$ the absence of an effect of exposure to toluene on LH pulse frequency suggests that intermittent acute exposure to toluene at concentrations up to 50 ppm probably does not acutely alter GnRH pulse frequency. Our results seem to contradict those of two epidemiological studies which found inverse associations between mean concentrations of $\mathrm{LH}, \mathrm{FSH}$, and testosterone and personal breathing zone toluene concentrations below the current threshold limit value. ${ }^{78}$ The peak blood toluene concentrations found in this study after 3 hours inhalation of $50 \mathrm{ppm}$ toluene $(0.23-7.96 \mathrm{nmol} / \mathrm{ml})$ were of the same order of magnitude as the blood toluene concentrations measured in those studies, suggesting that lower mean exposure concentrations in our study were not the cause of the difference. Several other factors may explain the disparities. Firstly, the workers in those studies were exposed to toluene on a daily basis for years. Although the authors found a significant association only with current toluene concentrations and not with lifetime exposure, it is possible that a longer period of exposure to toluene is required for effects on gonadotropin secretion to occur. Secondly, by contrast, Mørck and coworkers found cumulative lifetime exposure to toluene to be positively correlated with concentrations of plasma $\mathrm{FSH}$, but not with LH or testosterone. ${ }^{38}$ The discrepancies among these previous studies, which used single blood samples for gonadotropin measurements, and our study may also be due to the different sampling regimens used. Our technique is expected to provide much more precise estimates of mean hormone concentrations, as well as providing information about pulse amplitude and frequency. Thirdly, the workers in the studies of Svensson and coworkers were subject to fluctuating toluene concentrations, rather than constant concentrations as in our experiments. Although the median TWAs were $36 \mathrm{ppm}^{7}$ and $47 \mathrm{ppm}^{8}$ concentrations as high as 111 and $142 \mathrm{ppm}$, respectively, were found. It is possible that the peak concentration of exposure to toluene rather than TWA exposure is the important factor affecting gonadotropin secretion. Finally, the subjects in our study were exposed to toluene vapour at rest, whereas printing workers are engaged in physical activity while performing their work tasks. The increasing minute ventilation which occurs with increasing exertion results in greater absorbed doses of toluene for a given exposure. ${ }^{39}$ However, the measured whole blood concentrations of toluene in the studies of Svensson $e t a l^{7}{ }^{8}$ were of the 
same order of magnitude as the peak exposures in our study.

There are several important limitations to our study. Firstly, it is possible that the sample size was insufficient to detect a small effect of toluene on LH and FSH secretion. However, these studies had statistical power of at least $80 \%$ to detect a $12 \%$ change in mean LH concentrations and a $4 \%$ change in mean FSH concentrations in all three groups, and a $20 \%$, $30 \%$, and $100 \%$ change in mean LH pulse amplitude in women in the follicular phase, the luteal phase, and men, respectively. Changes of these magnitudes would be unlikely to push $\mathrm{LH}$ and $\mathrm{FSH}$ secretion out of the normal ranges reported ${ }^{15171820}$ and would thus represent subclinical effects. Secondly, the present results cannot rule out the possibility that exposures to higher concentrations of toluene or longer exposure periods would result in significant changes in gonadotropin secretion in men or women. Previous studies, however, have shown that other effects of toluene on the CNS can be found after $<3$ hours exposure. For example, controlled exposure studies in humans have found that visual vigilance task performance was impaired after inhaling 100 ppm for 2 hours and that reaction times were increased after 20 minutes inhalational exposures to $300 \mathrm{ppm}^{23}$ ATPase activities in primary astrocyte cultures ${ }^{40}$ and in synaptosomal membrane preparations ${ }^{41}$ were inhibited after 1 hour and 40 minutes exposure to toluene, respectively. Although no studies have been published describing effects of acute exposure to toluene on the catecholaminergic neurons in the hypothalamus involved in regulation of $\mathrm{GnRH}$ secretion, numerous studies have shown that $\mathrm{GnRH}$ secretion can be acutely altered by the administration of various pharmacological agents - such as the excitatory amino acid N-methyl-D,L-aspartate or the opiate antagonist naloxone. ${ }^{42}$ Subacutely, exposure to toluene increases noradrenaline concentrations and turnover in the hypothalamus. ${ }^{11}$ It may be that toluene induces such changes by mechanisms which do not operate acutely-such as alterations in the transcription of genes encoding enzymes in the noradrenaline synthetic or metabolic pathways. It is also possible that effects on LH and FSH secretion which have been noted by others were not mediated by hypothalamic actions of toluene, but rather by effects on the pituitary which do not occur acutely-such as alteration of gonadotropin subunit transcription or translation.

Another possible explanation for the discrepancy between previously published studies of the effect of workplace exposure to toluene on gonadotropin concentrations and the present study is confounding. We excluded subjects with conditions which might affect gonadotropin concentrations such as chronic illnesses, infertility, smoking, problem drinking, and age $>45$. We also used a randomised study design to minimise confounding by other unanticipated factors and used ANCOVA to control for covariates. Previous studies had controlled for age $^{8}$ and alcohol use, ${ }^{7}$ but not for smoking.
Smoking is known to result in lowered sperm density and increased testosterone concentrations, but has not been found to affect $\mathrm{LH}$ and FSH concentrations. ${ }^{44}$ Therefore, smoking is not likely to have been a significant confounder in previous studies. We also evaluated the potential covariates age, BMI, and adipose tissue fraction and found no significant effects on variables of $\mathrm{LH}$ or FSH secretion. The absence of an effect of age in our young subjects (only one $>40$ ) is not surprising. Previous studies have found that $\mathrm{LH}$ and $\mathrm{FSH}$ concentrations do not begin to increase significantly in women or men until ages $>40 . .^{303145}$ The relation between adiposity and reproductive endocrine function seems to be more complicated, with conflicting effects of obesity on gonadotropin secretion reported for both $\operatorname{men}^{33}$ and women. ${ }^{32}{ }^{34}$ Various criteria for obesity were used in these studies, but the BMIs generally were $>30$. As we had no male subjects with BMIs $>30$ and only three women with BMIs in this range, it is not surprising that we did not find significant associations between measures of adiposity and gonadotropin secretion.

In summary, exposure of men and normally cycling women of reproductive age to $50 \mathrm{ppm}$ toluene for 3 hours at rest did not result in abnormal patterns of episodic $\mathrm{LH}$ or $\mathrm{FSH}$ secretion. We did find a possible LH pulse frequency change in women during the luteal phase and subtle changes in mean concentration of LH in men exposed to toluene. As peripheral pulses of $\mathrm{LH}$ are preceded by hypothalamic $\mathrm{GnRH}$ pulses, these results also provide evidence that acute exposure to these concentrations of toluene are unlikely to affect GnRH pulse frequency in men or women in the follicular phase. The results further suggest that intermittent, acute exposures to concentrations up to $50 \mathrm{ppm}$ toluene, which are separated by sufficient time for toluene to be cleared from the body, are unlikely to result in physiologically important changes in gonadotropin secretion. This study cannot, however, rule out the possibility that longer durations of exposure or exposure during periods of physical exertion to comparable concentrations of toluene may have greater effects on gonadotropin secretion. Our findings indicate the need for further studies of reproductive function in workers exposed chronically to toluene to establish the safety of present occupational exposure limits.

We thank Dorothy McGuinness and Elizabeth Van Gaver of the Population Center for Research in Reproduction at the VA Puget Sound Health Care Center for their excellent technical help in performing the gonadotropin and testosterone assays and Mike Wessels for his technical expertise in performing the and Mike Wessels for his technical expertise in performing the
toluene assays. We thank Dr William Bremner, director of the toluene assays. We thank Dr William Bremner, director of the
Population Center, for his support and feedback on this study. We are also grateful to Dr Lianne Shepard for advice on the statistical analyses. Funding for this project was provided by NIOSH grant (to UL) 1 RO3 OH03468-01; by the Consortium for Risk Evaluation with Stakeholder Participation, US DOE Cooperative Agreement with the University of Washington DE-FCO1-95EW55084; and by a University of Washington NIEHS Center for Ecogenetics and Environmental Health (1 P30 ES07033-03) small grant (to UL). Additional support was provided by the Workers' Compensation Fund of Washington provided by the Workers Compensation Fund of Washington State, which is administered by the Washington Department of Labor and Industries. Portions of this work were presented at July 1998 . 
1 Barlow SM, Sullivan FM. Reproductive hazards of industrial chemicals. New York: Academic Press, 1982.

2 Huang XY. In fuence on benzene and tolue tive function of female workers in leathershoe-n ind industry [abstract]. Chinese fournal of Preventive Medicine 1991;25:89-91.

3 Sallmén M, Lindbohm M-L, Kyyrönen P, et al. Reduced fertility among women exposed to organic solvents. $A m \mathcal{F}$ Ind Med 1995;27:699-713.

4 Sallmén M, Lindbohm M-L, Anttila A, et al. Time to pregnancy among the wives of men exposed to organic solvents. Occup Environ Med 1998;55:24-30.

5 Smith EM, Hammonds-Ehlers $M$, Clark MK, et al. Occupational exposures and risk of female infertility. $\mathcal{F}$ Occup Environ Med 1997;39:138-47.

$6 \mathrm{Ng} \mathrm{TP}$, Foo SC, Yoong T. Menstrual function in workers exposed to toluene. BrF Ind Med 1992;49:799-803.

7 Svensson B-G, Nise G, Erfurth EM, et al. Neuroendocrine effects in printing workers exposed to toluene. Brf Ind Med 1992;49:402-8.

8 Svensson B-G, Nise G, Erfurth E-M, et al. Hormone status in occupational toluene exposure. Am f Ind Med 1992;22: in occup

9 Ameno K, Kiriu T, Fuke C, et al. Regional brain distribution of toluene in rats and in a human autopsy. Arch Toxicol 1992;66:153-6.

10 Stepanov MG, Altukhov VV, Proimina FI, et al. Physiologic mechanisms of the reaction of the reproductive system in female rats to chronic exposure to low doses of toluene [abstract]. Fiziologicheskii Zhurnal SSSR Imeni IM Sechenova 1990;76:1096-102

11 Andersson K, Fuxe K, Toftgård R, et al. Toluene-induced activation of certain hypothalamic and median eminence catecholamine nerve terminal systems of the male rat and its effects on anterior pituitary hormone secretion. Toxicol Lett 1980;5:393-8.

12 von Euler G, Fuxe K, Hansson T, et al. Effects of chronic toluene exposure on central monoamine and peptide toluene exposure on central monoamine and peptide receptors and their inter
cology 1988;52:103-26.

13 Weiner RI, Findell PR, Kordon C. Role of classic and peptide neuromediators in the neuroendocrine regulation of LH and prolactin. In: Knobil E, Neill JD, eds. The physiol ogy of reproduction, 2nd ed. New York: Raven Press,

14 Santen RJ, Bardin CW. Episodic luteinizing hormone secretion in man: pulse analysis, clinical interpretation, physiologic mechanisms. F Clin Invest 1973;52:2617-28.

15 Matsumoto AM, Bremner WJ. Modulation of pulsatile gonadotropin secretion by testosterone in man. $f$ Clin Endocrinol Metab 1984;58:609-14.

16 Soules MR, Steiner RA, Cohen NL, et al. Nocturnal slowing of pulsatile luteinizing hormone secretion in women during the follicular phase of the menstrual cycle. $f$ Clin Endocrinol Metab 1985;61:43-9.

17 Spratt DI, O'Dea LSL, Schoenfeld D, et al. Neuroendocrine-gonadal axis in men: frequent sampling of LH, FSH, and testosterone. Am 7 Physiol 1988;254:E65866 .

18 Filicori M, Santoro N, Merriam GR, et al. Characterization of the physiological pattern of episodic gonadotropin secretion throughout the human menstrual cycle. F Clin Endocrinol Metab 1986;62:1136-44.

19 Plant TM. Gonadal regulation of hypothalamic gonadotropin-releasing hormone release in primates. Endocr Rev 1986;7:75-88.

20 Soules MR, Steiner RA, Clifton DK, et al. Progesterone modulation of pulsatile luteinizing hormone secretion in normal women. $\mathcal{F}$ Clin Endocrinol Metab 1984;58:378-83.

21 Hotchkiss J, Knobil E. The menstrual cycle and its neuroendocrine control. In: Knobil E, Neill JD, eds. The physiology of reproduction, 2nd ed. New York: Raven Press, 1994:711-49.

22 Pierce C, Dills $\mathrm{R}$, Morgan $\mathrm{M}$, et al. Interindividual differences in 2H8-toluene toxicokinetics assessed by a semi-empirical physiologically-based model. Toxicol Appl Pharmacol 1996;139:49-61.

23 American Conference of Governmental Industrial Hygienists. Documentation of the threshold limit values and biological exposure indices, 6th ed. Cinncinnati, OH: ACGIH, 1991

24 Agency for Toxic Substances and Disease Registry. Toxicological profile for toluene (update).Atlanta: US Department of Health and Human Services, Public Health Service, ATSDR, 1994. (ATSDR/TP-93/14 ed.)
25 Morgan M, Dills RL, Kalman DA. Evaluation of stable isotope-labeled probes in the study of solvent pharmacokinetics in human subjects. Int Arch Occup Environ Health 1993;651:S139-42.

26 Matsumoto AM, Paulsen CA, Hopper BR, et al. Human chorionic gonadotropin and testicular function: stimulation of testosterone, testotsterone precursors, and sperm production despite high estradiol levels. f Clin Endocrinol Metab 1983;56:720-8.

27 Dills RL, Kent SD, Checkoway H, et al. Quantification of volatile solvents in blood by static headspace analysis. Tantala 1991;38:365-74.

28 Van Cauter E. Estimating false-positive and false-negative errors in analyses of hormonal pulsatility. Am f Physiol 1988;254:E786-94.

29 Durnin JVGA, Womersly J. Body fat assessed from total body density and its estimation from skin fold thickness: measurements on 481 men and women aged from 16 to 72 years. Toxicol Appl Pharmacol 1974;120:266-73.

30 Klein NA, Battaglia DE, Clifton DK, et al. The gonadotropin secretion pattern in normal women of advanced reproductive age in relation to the monotropic FSH rise. Fournal of the Society for Gynecologic Investigations 1996;3:27-32.

31 Deslypere JP, Vermeulen A. Leydig cell function in normal men: effect of age, life style, residence, diet, and activity. $\mathcal{F}$ Clin Endocrinol Metab 1984;59:955-62.

32 Grenman S, Ronnemaa T, Irjala K, et al. Sex steroid, gonadotropin, cortisol, and prolactin levels in healthy, massively obese women: correlation with abdominal fat cell size and effect of weight reduction. F Clin Endocrinol Metab 1986;63:1257-61.

33 Vermeulen A, Kaufman JM, Deslypere JP, et al. Attenuated luteinizing hormone ( $\mathrm{LH}$ ) pulse amplitude but normal LH pulse frequency, and its relation to plasma androgens in hypogonadism of obese men. F Clin Endocrinol Metab 1993; 76:1140-6.

34 Unzer SRM, dos Santos JE, Moreira AC, et al. Alterations in plasma gonadotropin and sex steroid levels in obese ovulaory and chronically anovulatory women. 7 Reprod Med 1995;40:516-20.

35 Rossmanith WG, Liu CH, Laughlin GA, et al. Relative changes in LH pulsatility during the menstrual cycle: using data from hypogonadal women as a reference point. Clin Endocrinol 1990;32:647-60.

36 Veldhuis JD, Evans WS, Demers LM, et al. Altered neuroendocrine regulation of gonadotropin secretion in women distance runners. F Clin Endocrinol Metab 1985;61: $557-63$

37 Southworth MB, Matsumoto AM, Gross KM, et al. The importance of signal pattern in the transmission of endocrine information: pituitary gonadotropin responses to continuous and pulsatile gonadotropin-releasing hormone. F Clin Endcrinol Metab 1991;72:1286-9.

38 Mørck HI, Winkel P, Gyntelberg F. Health effects of toluene exposure. Dan Med Bull 1988;35:196-200.

39 Mar TF, Pierce CH, Morgan MS, et al. The effects of exercise and gender on toluene toxicokinetics in human volunteers [abstract]. Toxicol Sci 1998;42(suppl 1):142.

40 Vaalavirta L, Tahti H. Effects of selected organic solvents on the astrocyte membrane ATPase in vitro. Clin Exp Pharmacol Physiol 1995;22:293-94.

41 Edelfors S, Ravn-Jonsen A. Effects of simultaneous ethanol and toluene exposure on nerve cells measured by changes in synaptosomal calcium uptake and $\left(\mathrm{Ca}^{2+} / \mathrm{Mg}^{2+}\right)$-ATPase activity. Pharmacol Toxicol 1991;69:90-5.

42 Gay VL, Plant TM. N-methyl-D,L-aspartate elicits hypothalamic gonadotropin-releasing hormone release in pothalamic gonadotropin-releasing hormone release in
prepubertal male rhesus monkeys (Macaca Mulatta). Endocrinology 1987;120:2289-96.

43 Karahalios DG, Levine JE. Naloxone stimulation of in vivo LHRH release is not diminished following ovariectomy. Neuroendocrinology 1988;47:504-10.

44 Vogt H-J, Heller W-D, Borelli S. Sperm quality of healthy smokers, ex-smokers, and never-smokers. Fertil Steril 1986; 45:106-10.

45 Schmidt PJ, Gindoff PR, Baron DA, et al. Basal and stimulated gonadotropin levels in the perimenopause. Am 7 Obstet Gynecol 1996;175:643-50.

46 Blank DM, Clark RV, Heymsfield SB, et al. Endogenous opioids and hypogonadism in human obesity. Brain Res Bull 1994;34:571-4. 